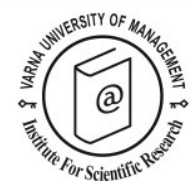

\title{
Key destination attributes of behavioural intention: An application of neural networks
}

\author{
Maria M. Santos Silva ${ }^{1}$, Tahir Albayrak ${ }^{2 *}$, Meltem Caber $^{3}$ and Luiz Moutinho ${ }^{4}$
}

Received: 01/04/2016 Accepted: 21/05/2016

\footnotetext{
1 Assistant professor, Faculty of Economics of the University of Coimbra. Av. Dias da Silva, Coimbra, Portugal; email address: nelinha@fe.uc.pt.

2 Associate professor, Akdeniz University, Tourism Faculty, Campus. Antalya, Turkey; email address: tahiralbayrak@akdeniz.edu.tr

3 Associate professor, Akdeniz University, Tourism Faculty, Campus. Antalya, Turkey; email address: meltemcaber@akdeniz.edu.tr

4 Professor, DCU Business School, Dublin City University, Collins Avenue Dublin 9, Ireland; email address: luiz.moutinho@dcu.ie

* Corresponding author
}

\begin{abstract}
In the tourism literature artificial neural networks (ANNs) are mainly employed in forecasting and market segmentation. Hitherto, no existing research applies ANNs in assessing the effect of destination attributes on customer behavioural intention. Thus, the aim of this study is to identify the main destination attributes, and to evaluate the effects of these attributes, customer satisfaction and perceived value on behavioural intention by using ANNs. Data obtained from 332 foreign tourists visiting Antalya-Turkey were analyzed for exploring the relationships among the research variables. ANN results show that five explanatory variables (shopping, transportation, accommodation, customer satisfaction, perceived value), which are the input nodes, correspond to output node of behavioural intention. Findings indicate the role of value perception and the importance of the basic functional attributes in the formation of behavioural intention, and the strength of ANNs in terms of exploration and prediction of tourist behaviour against regression analysis.
\end{abstract}

(C) 2016 Varna University of Management. All rights reserved

Keywords: destination, artificial neural networks, service quality, behavioural intention, value perception, customer satisfaction

Citation: Santos Silva M., T. Albayrak, M. Caber and L. Moutinho (2016) Key destination attributes of behavioural intention: An application of neural networks. European Journal of Tourism Research 14 , pp. $16-28$

\section{Introduction}

Knowledge discovery in databases in general, and data mining in particular, constitutes a set of principles and techniques which can be employed to retrieve valuable information from vast amounts of stored data (Čech \& Burěs, 2009). The information-intensive nature of tourism industry (Law, Mok, \& Goh, 2007) 
supports the necessity of using data mining techniques for understanding, clarifying, and estimating tourist behaviour. Moreover, by internalizing inter and cross-disciplinary characteristics of tourism research, academics may use the benefit of various data mining techniques adapted from other disciplines to overcome the complexity of the tourism phenomenon (Uysal, 2004). Pyo, Uysal and Chang (2002) state that data mining is a useful tool for destination management and that, in the future, more tourist destinations will adopt it. Nevertheless, there still remains a need for studies which provide insights into the complicated relationships between various variables at the destinations and which explain their impacts on tourist behaviour.

In this sense, the artificial neural network (ANN) is one of the popular data mining techniques which fit cross-disciplinary research methods. ANNs are inspired by the architecture of the human brain and distributed informationprocessing systems composed of many simple computational elements interacting across weighted connections (Venugopal \& Baets, 1994). The strength of ANNs is their ability to offer good results in cases of complicated, mutual interactions between multi-variables or in the absence of a unique solution cluster. Those kinds of situations are very common in destination management studies as tourism destinations are the strategic units where tourists are offered all the relevant products and/or destination attributes which they may expect in holiday activity (Bieger, 1998).

Although ANN is a suitable technique for the cases of complicated, mutual interactions between multi-variables, it was mostly used for tourist forecasts in the literature (e.g. Law, 2000; Duo, Guo, \& Wang, 2007). No study exists which assesses the influence of destination attributes on tourists' behavioural intention by using ANNs. Therefore, the objectives of this study are: (1) to determine the main destination attributes and to assess the effects of these attributes, customer satisfaction, and perceived value on behavioural intention by using ANN; (2) to demonstrate the role, importance and sophistication of the ANNs in clarifying the determinant variable of customer behavioural intention, and (3) to show the efficiency of ANNs by a comparison with traditional regression analysis results.

In this study, the ANNs technique was preferred for several reasons. Firstly, the input data was judgmental rather than factual, which resulted in some "fuzziness" in the data. The numbers used in the analysis were indicators of feelings or perceptions rather than exact observed values. It is more important to look for overall patterns in the data rather than to try to formulate equations relating inputs to output. Secondly, the use of a neural network allows the labelling of hidden layer nodes (Mitchell et al., 1999). Clusters of factors contributing to each hidden node could be examined to see, if they reveal an underlying management philosophy which would impact either positively or negatively to behavioural intention.

In the following section, the relationship amongst destination attributes, customer satisfaction, perceived value, and behavioural intention is documented. The use of ANNs in consumer behaviour and tourism literature is summarized in the next section. Analyses results are presented in the later section. Finally, the study is concluded with the discussion of the findings and (theoretical and managerial) implications.

\section{The relationship amongst destination attributes, customer satisfaction, perceived value, and behavioural intention}

Destination attributes are accepted as: (a) customer decision factors (Coshall, 2000), (b) image formation elements (Choi, Chan, \& Wu, 1999), and (c) 'pull' motivation factors depending on the academics' research purposes (Klenosky, 2002). While people decide where to go, they are presumed to consider various destination attributes such as the ease of accessibility, climate, and infrastructure, natural and cultural values. Therefore, richness and attractiveness of destination attributes may increase popularity and competitiveness of an area. For example, in one of the destination image models, Crouch and Ritchie (1998) proposed the main attributes of the convention, exposition and meeting destinations as: accessibility, local support, extra-conference opportunities, 
Key destination attributes of behavioural intention: An application of neural networks.

accommodation facilities, meeting facilities, information, site environment, and others. Destination image which is "perceived as a holistic construct, including tangible and intangible destination attributes as well as common and unique characteristics" (Pikkemaat, 2004: 99) has been a widely investigated topic by the researchers as well. While tangible attributes of the destinations are categorized in 'functional'; intangible attributes are categorized in 'psychological' factors, and both of these form the destination image. A literature review on destination image by Pike (2002) showed that majority of the studies were conducted by using multi-attribute models, although criticism of the use of attribute lists still continues. However, as Echtner and Ritchie (2003) noted, destination image should be envisioned and discussed both attributebased and holistic perspectives.

While many studies examine attributes of the destinations in the context of image, growing number of studies propose destination choice or evaluation models containing functional and psychological destination attributes (e.g. Beerli \& Martin, 2004; Ahn, Ekinci, \& Li, 2013; Eusébio \& Vieira, 2013). In the majority of the studies Importance-Performance Analysis (Litvin \& Ling, 2001; Fallon \& Schofield, 2006; Meng, Tepanon, \& Uysal, 2008) and Repertory Grid Analysis (Pike, 2003) are used for the identification of attributes' importance and performance.

In the perspective of motivation, destination attributes are 'pull' factors of travel motivation in the Dann's (1977) push and pull motivation theory. According to this theory, travel motivations comprise of internal 'push' and external 'pull' forces. In addition to pull attributes' identification (Klenosky, 2002), some researchers attempt market segmentation (Baloglu \& Uysal, 1996), and comparison of cultural differences (You et al., 2000) by adapting this theory.

Perceived performance of the destination attributes is directly related to service-oriented constructs such as customer satisfaction, perceived value, and behavioural intention (Chen \& Tsai, 2007; Žabkar, Brenčič, \& Dmitrović, 2010). In the tourism literature, the bivariate relationships with behavioural intentions and proposed antecedent variables like destination attributes' performance, value, and satisfaction were widely examined (Hutchinson, Lai, \& Wang, 2009). Many study results have shown that satisfaction, value and quality were good predictors of customer behavioural intention (Bigne et al., 2001; Cronin, Brady, \& Hult, 2000; Baker \& Crompton, 2000). For example, Eusebio and Vieira (2013) stated that satisfaction was a necessary but non-sufficient condition; good performance of destination attributes was also important for recommending a destination. On the other hand, the results of Um, Chon and Ro's (2006) study showed that repeat visits were affected more by destination attributes' performance than overall satisfaction. Recently, Moutinho, Albayrak and Caber (2012) generated a conceptual model to determine the perceived performance of destination attributes and assessed its effect on perceived value, customer satisfaction and behavioural intention. They showed that perceived value was an important determinant of customer satisfaction and behavioural intention.

\section{Use of artificial neural networks in consumer behaviour and tourism literature}

The aim of ANN, which is embedded in physiology and psychology, is to work with a direct analogy of the human brain as a set of interconnected processing units, usually called nodes, neurons or cells. A neuron executes two operations on the receiving values. While, "combination function", consists of summing its inputs weighted by the correspondent links of the neuron, "activation function", applies a function to the value obtained in the former operation and produces the output of the neuron.

ANNs have been successfully applied in a broad range of domains including classification, data mining, optimization and time series prediction. Since the mid-nineties, they have also been applied to marketing problems, such as modelling consumer responses to market stimuli (Curry \& Moutinho, 1993), predicting consumer choice (West, Brockett, \& Golden, 1997), new product development (Thieme, Song, \& Calantone, 2000), marketing strategy (Li, 2000), sales forecasting (Kuo, 2001), and 
market segmentation (Dasgupta, Dispensa, \& Ghose, 1994; Boone \& Roehm, 2002). As researchers realize the flexibility of that methodology and its applicability to a wide range of research areas, the number of studies employing ANNs increased considerably. Researchers have highlighted their performance, not only in the domain of consumer behaviour, but also in the tourism marketing and management areas.

Most of the literature on tourism employs ANN to forecast tourism demand by using time series. Law and Au (1999), for example, used ANNs to forecast Japanese tourist demand to Hong Kong. Palmer, Montano and Sese (2006) who used ANNs to predict tourist expenditure in the Balearic Islands indicated that ANNs were effective and flexible instruments for forecasting in tourism. In addition, Duo et al. (2007) presenting a prediction on room occupancy rate in the same city, showed that the neural model outperforms other traditional statistical techniques. Moutinho et al. (2008), using neural networks, investigated the determinants of Mainland Chinese arrivals to Taiwan and forecasted corresponding tourism demand. As neural networks are adequate in handling nonlinear data, without making a priori assumptions about the relationships between inputs and outputs, Huarng, Moutinho and $\mathrm{Yu}$ (2007) offered an application of the neural network based fuzzy time series model to forecast international tourist arrivals to Taiwan.

However, the use of ANNs other than forecasting is still limited. One exception is Tsaur, Chiu and Huang's (2002) study which investigated the determinants of business tourists' loyalty toward international hotels. These authors also compared the results of ANNs to logistic regression models and concluded that ANNs outperform regression models as it considered non-linear interactions. ANNs were also used for market segmentation in tourism literature, and their performance was shown to be satisfactory (Mazanec, 1992; Bloom, 2005). Recently, ANNs have been used to identify critical service attributes by considering their non-linear effects on overall customer satisfaction (Deng \& Pei, 2009; Mikulić \& Prebežac, 2012).

\section{Methodology}

The target population of this study was foreign tourists visiting Antalya - Turkey. 45 items which were adapted from the literature (Kau \& Lim, 2005; Tosun et al., 2007; Truong \& Foster, 2006; Heung, Qu, \& Chu, 2001) for assessing destination attributes were reduced to 33 items by conducting three focus group meetings with a total of 24 sector professionals and three academics. Items of the scale were translated from Turkish into German, Russian, English, and Dutch and controlled by native-speaker tourist guides. Behavioural intention was under particular examination of the outcome of the holiday experience in this study, was measured by two constructs; the likelihood of future visits and the likelihood of recommendation dimensions (Boulding et al., 1993).

Single item was used for the measurement of respondents' perceived value and overall satisfaction (Weaver, Weber, \& McCleary, 2007). A five-point Likert scale ranging from five (totally agree) to one (totally disagree) was used to assess destination attributes and other variables. By relying on the recommendations of the directorship of Touristic Enterprises and Hoteliers Association of Side-Manavgat, which has established by the hotel managers located in Side - Antalya, 38 hotels were selected for survey. Totally 8120 questionnaires were sent to the hotels with a cover letter, and hotel managements were requested to distribute one questionnaire to each hotel room. Out of 1905 returned questionnaires, 332 useable data were remained by the elimination of uncompleted questionnaires. The low rate of return happened by two main reasons in this study. Firstly, physical distance between the area of hotels and the researchers' city of residence negatively affected the management and control of the study, where mostly the hotel staff played role on distribution and collection of the questionnaires. Secondly, completion of the questionnaire depending on the willingness of the hotel guests made it difficult to achieve the targeted rate of return.

\section{Results}

\section{Exploratory factor analysis}

By using 33 items, exploratory factor analysis with varimax rotation was employed to identify the destination attributes. Items which had 
Key destination attributes of behavioural intention: An application of neural networks.

Table 1. Exploratory Factor Analysis Results

\begin{tabular}{llccc}
\hline Dimensions & Items & $\begin{array}{c}\text { Factor } \\
\text { Loading }\end{array}$ & $\begin{array}{c}\text { Variance } \\
\text { Explained }\end{array}$ & Mean \\
\hline Shopping & Methods of the shopkeepers to attract customers & 0.825 & 18.78 & 3.16 \\
& Attitudes of the shopkeepers towards to tourists & 0.891 & & \\
& Honesty of the shopkeepers & 0.865 & & \\
\hline Accommodation & General cleanliness of the hotel & 0.858 & 18.32 & 4.28 \\
& Food and beverage quality at the hotel & 0.855 & & \\
& Attitudes of the hotel staff & 0.831 & & \\
\hline Local & Comfort of the local vehicles & 0.770 & 18.10 & 3.60 \\
Transportation & Frequency of the transport services & 0.876 & & \\
& Generality of the transportation system & 0.881 & & \\
\hline Information & Informative signs and symbols & 0.835 & 11.73 & 3.53 \\
& Ways of pedestrians and night lightning & 0.811 & & \\
\hline Health and & Cleanliness of the food and beverage facilities & 0.804 & 11.44 & 3.58 \\
Hygiene & Cleanliness of the public toilets & 0.823 & & \\
& The Kaiser-Meyer-Olkin measure of sampling adequacy & 0.828 & \\
The Bartlett's test of sphericity (significance level) & $4371.9(0.000)$ & \\
\hline
\end{tabular}

Table 2. Factors Determining Behavioural Intention

\begin{tabular}{lcccc}
\hline Variables & $\mathbf{B}$ & $\boldsymbol{\beta}$ & $\mathbf{t}$ & $\mathbf{p}$ \\
\hline Constant & -0.200 & & & \\
Shopping & 0.074 & 0.077 & 2.518 & $0.012^{\star *}$ \\
Accommodation & 0.040 & 0.034 & 1.120 & 0.263 \\
Transportation & 0.062 & 0.050 & 1.611 & 0.108 \\
Information & 0.054 & 0.049 & 1.615 & 0.107 \\
Health and Hygiene & -0.062 & -0.053 & -1.778 & 0.076 \\
Customer satisfaction & 0.361 & 0.365 & 7.838 & $0.000^{*}$ \\
Perceived value & 0.479 & 0.496 & 10.252 & $0.000^{*}$ \\
\hline
\end{tabular}

Dependent variable is behavioural intention; $R^{2}$ : 0.787; F: $170.859(p<0.01)$

${ }^{*} p<0.01 ;{ }^{* *} p<0.05$

communalities below than 0.50 were eliminated as not having sufficient explanation (Hair et al., 1998). Moreover, items that had below than 0.707 (square root of 0.5 ) factor loadings were eliminated for ensuring construct validity (Shimp \& Sharma, 1987). After this process, five dimensions (representing destination attributes) which explain $78.37 \%$ of the total variance were obtained. These dimensions were named as 'Health and Hygiene', 'Shopping', 'Information', 'Local Transportation', and 'Accommodation' (Table 1).

Regression analysis results

Before conducting ANN analysis, the relationship between input variables of ANN (shopping, accommodation, transportation, information, health and hygiene, customer satisfaction, and perceived value) and behavioural intention was examined by regression analysis. As shown in Table 2, the model explains $78.7 \%$ of the variance. While perceived value and customer satisfaction are the strongest predictors of behavioural intention, most of the destination attributes (accommodation, transportation, information, health and hygiene) do not have significant effects on behavioural intention.

\section{Neural network approach}

For ANN analysis, firstly, the data should be divided into the training and validation sets. Baum and Haussler (1989) proposed the 
following formula, on the basis of the desired accuracy:

$$
P>|W| /(1-a)
$$

where $P$ denotes the size of the training set, $|\mathrm{W}|$ the number of weights to be trained and a the expected accuracy on test set.

In this study, the number of weights to be trained was 18 and the expected accuracy was 0.90 . Therefore, $P$ should have been above than $180(54.2 \%)$. If the size of the training set is too small, the network cannot learn and in front of new examples it will be unable to generalize. Considering the above result and the preceding assumptions, it was decided that the data were divided into a training set of 232 examples ( $70 \%$ of the sample) and a test set of 100 examples to validate the model. A multiple feedforward network method was used as the architecture of ANN. One advantage of this methodology is its ability to serve as 'universal approximators'. The optimal fit between inputs and output was obtained using a multiple feedforward network with a single hidden layer of three neurons. This was thought to be a reasonable number of intermediate variables that could be identified and labelled. Increasing the number of hidden neurons beyond three did not improve the capacity of generalization of the network as well as increasing the number of hidden layers. In terms of dealing with nonlinearity in the data, networks with fewer than the required hidden nodes will be unable to generalize the nonlinearity and with too many nodes can result in overfitting (Wang, 1998). Moreover, Rumelhart, Widrow and Lehr (1994) stated that minimal networks provide more efficient generalization performance than more complex networks do. Besides, smaller networks learn and operate more quickly with less complexity and are simpler to interpret in terms of rules (Hagiwara, 1993; Looney, 1996).

The main neural network had five input nodes which were; Shopping (SH), Transportation (TP), Accommodation (AC), Customer Satisfaction (CS) and Perceived Value (PV). The single output node corresponded to behavioural intention. Figure 1 depicts this neural architecture. The two explanatory variables (Health and Hygiene, Information) were eliminated from the final model due to their minor role and impact.

The learning rate and the momentum term of the main and space networks were initialized to 0.7 and 0.5 , respectively, decaying the latter, automatically, $1 \%$ every 200 epochs (one complete presentation of the entire training set during the learning process is called an epoch).

Input layer

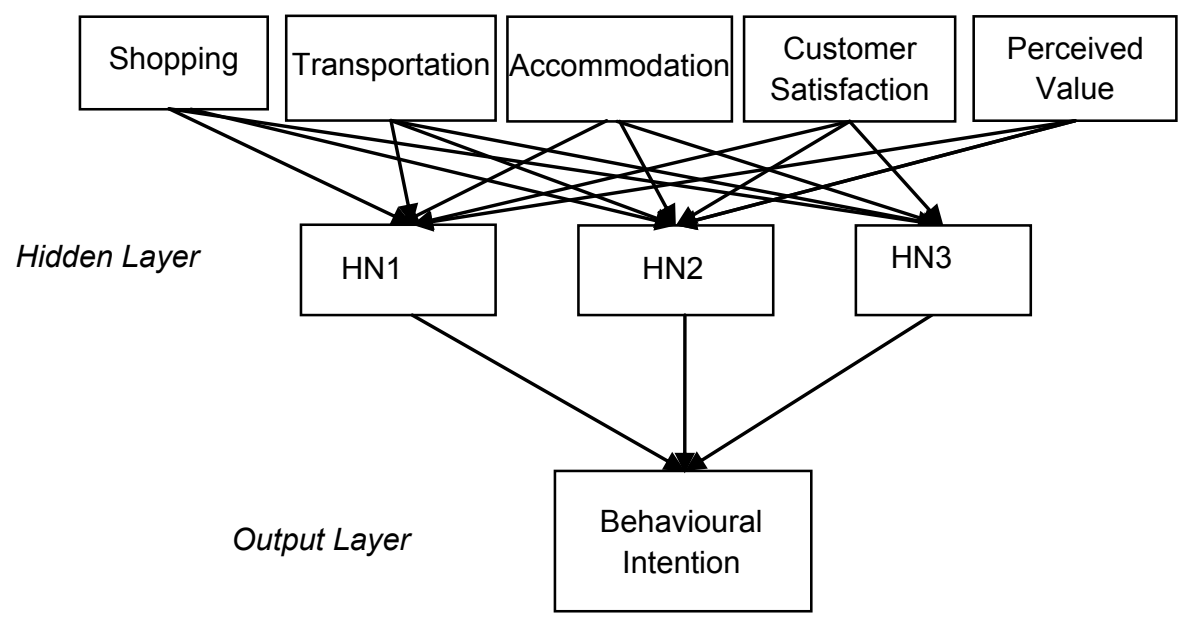

Figure 1. The Main Neural Network 
The multiple backpropagation algorithm was allowed to run until it appeared that no further improvement could be made to the quality of its predictions.

\section{ANNs results}

Table 3 shows the weights of the network links between the neurons as well as the contributions made by the explanatory variables. The weights resulted between -0.6 and 1.3. The root mean square error for the test data was 0.0569. A goodness of fit coefficient, $R^{2}$, was computed to evaluate the performance of the multiple feedforward network. The $R^{2}$ value, similar to the $R^{2}$ coefficient provided in multiple regression analysis, that is:

$$
R^{2}=1-\frac{R M S E}{s_{y}^{2}}
$$

where $s^{2} y$ is the variance of the desired output for the test data, was 0.9 for behavioural intention. Consequently, the neural model explains about $90 \%$ of the variance of output variable. In addition, visual inspection of the residual plots confirms the model, since there is little autocorrelation. The values and signs (+ or -) of the network connection weights between the input nodes and the hidden nodes are used to infer suitable intermediate attributes. Observing the resulting neural network topology derived from the findings of the study, the authors found that Customer Satisfaction as the input layer has a total contribution (the highest) of 2.130 to the three neurons comprising the hidden layer (Table 3). The second highest total contribution derives from the Accommodation factor (1.976). Transportation and Perceived Value have also significant very similar contributions of 1.653 and 1.643 respectively, whereas the Shopping has the lowest level of impact on the hidden layer (0.825).

The hidden neuron 1 (HN1), labelled 'Value for Money' is so referred because its contributory weights are mainly supported by the input variables; Perceived Value (+1.046), and Customer Satisfaction $(+0.698)$. These factors characterize the judgment of the tourists for the services they obtained, and as measured by his/her attitudinal development. Accommodation and Transportation also displayed positive weights (albeit small). Only Shopping (-0.327) displayed an inhibitory weight in its connectedness to HN1.

The contributory and inhibitory weights linked to the input variables of the neural model, affecting the hidden neuron two (HN2), illustrate that Accommodation (+1.142), and Transportation $(+1.238)$ are the outstanding contributory weights. The other neurons included within the input layer have showed

Table 3. Neural Network Weights between Input and Hidden Neurons

from the input layer

\begin{tabular}{lcccccc}
\hline to the hidden layer & bias & Shopping & Transportation & Accommodation & $\begin{array}{l}\text { Customer } \\
\text { Satisfaction }\end{array}$ & \multicolumn{2}{l}{$\begin{array}{l}\text { Perceived } \\
\text { Value }\end{array}$} \\
\hline 1st neuron & 0.089 & -0.327 & 0.186 & 0.257 & 0.698 & 1.046 \\
2nd neuron & -0.139 & -0.009 & 1.238 & 1.142 & -0.853 & -0.468 \\
3rd neuron & 0.885 & 0.489 & -0.229 & -0.577 & 0.579 & -0.129 \\
\hline Total contribution & 1.113 & 0.825 & 1.653 & 1.976 & 2.130 & 1.643 \\
\hline
\end{tabular}

Table 4. The Impacts of the Hidden Neurons on Behavioural Intention from the hidden layer

\begin{tabular}{lcccc}
\hline To the output layer & Bias & $\begin{array}{c}\text { 1st neuron } \\
\text { (Value for Money) }\end{array}$ & $\begin{array}{c}\text { 2nd neuron } \\
\text { (Basic Functional } \\
\text { Attributes) }\end{array}$ & $\begin{array}{c}\text { 3rd neuron } \\
\text { (Tourist Behaviour } \\
\text { Multidimensionality) }\end{array}$ \\
\hline Behavioural Intention & -2.271 & 3.466 & 2.604 & 2.541 \\
\hline
\end{tabular}


negative weights, where Customer Satisfaction $(-0.853)$, had the highest negative impact to the whole neural network topology. Shopping exhibits an inhibitory weight of -0.009 considerably lower than the negative effect derived from Perceived Value (-0.468), which could mean that Shopping by itself tends to be a quasi-irrelevant factor in terms of behavioural intention to holiday in a tourism destination which is positioned as having many enclosed resorts as its main attraction. Based this assessment of the overall input factors upon the hidden layer, HN2 was labelled as 'Basic Functional Attributes'.

Furthermore, the outstanding contributory and inhibitory weights which are linked to the input variables of the neural model, affecting HN3, reveal that there is only a marginal difference in the balance between positive and negative impacts. In this case, there is a slim positive skewness. This limited positive stance is derived from Customer Satisfaction (+0.579) and Shopping $(+0.489)$. In this case the inhibitory weights come from Accommodation ($0.577)$, Transportation (-0.229) and Perceived Value (-0.129). Overall, all of the contributory and inhibitory weights present low values of impact which assesses the global neural network topology. As a result, this hidden neuron (HN3) is hereby labelled as 'Tourist Behaviour Multidimensionality', since it represents the varied, diverse, non-linear, and even sometimes, chaotic nature of human/consumer needs, attitudes and motivations.

Examining the impact of the three hidden neurons on the output factor - behaviour intention - one can clearly deduce that the issue of 'Value for Money' (+3.466) is the paramount trigger when inducing tourists to the development of purchase intention towards a tourism destination (Table 4). The second highest level of impact derived from the hidden layer onto the sole output variable is associated with 'Basic Functional Attributes' (+ 2.604) which really lay the critical underpinnings for tourists to perceive that they are getting good value for money. Finally, the lowest level of impact (as compared to the other remaining neurons, but still containing a high positive contribution) can be found in HN3 which has been previously named as 'Tourist Behaviour Multidimensionality' (+ 2.541).

\section{Discussion}

This study aims to identify the main destination attributes, and to determine the effects of destination attributes, customer satisfaction and perceived value on behavioural intention by using an ANN topology. In addition, this study demonstrates the role, importance and sophistication of the ANNs. For showing the strength of ANNs against the other techniques, the results of regression analysis were presented as well.

Firstly, with the purpose of achieving study objectives, the main destination attributes were obtained, namely; 'Health and Hygiene', 'Shopping', 'Information', 'Local Transportation', and 'Accommodation' by using exploratory factor analysis. The regression analysis explained $78.7 \%$ of the behavioural intention, while perceived value and customer satisfaction were the main determinants. Following, ANN analysis was performed for clarifying the impacts of destination attributes, customer satisfaction and perceived value on behavioural intention. In the research model, 3 hidden neurons were explored, where 'Health and Hygiene' and 'Information' attributes were eliminated, because of their insignificant influences on behavioural intention.

The first hidden neuron was mainly supported by perceived value and customer satisfaction variables, and named as 'Value for Money' for this reason. Other two hidden neurons were similarly named in accordance with their determinant input neurons, respectively as 'Basic Functional Attribute' and 'Tourist Behaviour Multidimensionality'.

The results of the analysis indicate that the hidden neuron 'Value for Money' was the most important determinant of behavioural intention. This result is consistent with Kozak and Rimmington (2000) who qualify 'overall value for money' as a critical element for tourist future behaviour, as well as Yoon and Uysal (2005) who show that 'overall satisfaction' is a vital element for behavioural intention. Results indicate that customer satisfaction and perceived value are closely related to each 
Key destination attributes of behavioural intention: An application of neural networks.

other. Thus, achieving only customer satisfaction will not positively affect behavioural intention, since customers also expect to get the benefits of a product or service that they paid for. Therefore, offering extra products or services to tourists, may increase value perception.

Furthermore, the analysis of the results show that the two hidden neurons 'Basic Functional Attributes' and 'Tourist Behaviour Multidimensionality' are the important determinants of behavioural intention, although their values are lower than the other hidden neuron 'Value for Money'. This finding underlines the role and significance of the main destination attributes on behavioural intentions of tourists. Without achieving minimum requirements for destination attributes, destination authorities cannot generate positive behavioural intention. This result complies with not only a nomological rationale but also with a pragmatic view of the tourism business system. This means that the overall perceived value by tourists represents a higher level of abstraction in terms of consumer decision making, which is subsequently dissected into tangible functional tourism product attributes and benefits. However, there is the existence of a myriad of tourist profiles and constellation of motives and purchase criteria which are disseminated in multiple tourist segments. These different cohorts seek specific characteristics within the bundle of features usually offered by the tourism industry. This fact creates the so-called multidimensionality of tourists' behavioural preferences.

In addition, the comparison of ANNs and regression analysis results supplies evidence to ANNs strength against regression analysis. Thus, in accordance with the previous studies (Tsaur, Chiu, \& Huang, 2002; Duo et al., 2007), findings of this study confirm the outperforming performance of ANNs compared to traditional regression analysis. Besides, ANNs identify existing patterns better than regression analysis, and offer better estimates for the prediction bias and accuracy, as Uysal and El Roubi (1999) noted before. However, the academics are strongly recommended to conduct more number of studies where ANNs and other analysis techniques are compared in terms of consistency and accuracy of the results.

This study has also some unavoidable limitations like any other studies. For example, three items of the questionnaire are doublebarrelled (e.g. 'Informative signs and symbols', 'Ways of pedestrians and night lightning', and 'Food and beverage quality at the hotel'). Although these items are purposely offered for increasing the clarity, they also negatively impact the validity and reliability of the scale. Moreover, ANN has its own limits. In the present study, the results are dependent to initial values of the parameters of the neural network (e.g. learning rate, momemtum term) which were selected for the analysis. Moreover, in building the architecture of the neural network, the authors had to decide how many hidden layers and neurons should have been chosen in each hidden layer to build a feed forward network.

\section{Theoretical implications}

Although tourism management researches show multidisciplinary characteristics, the adaption of analytical techniques from other disciplines is very limited. The ANN approach which has been previously used in physiology and psychology has become an exceptional example in that context. However, studies which employ ANNs in the destination management and tourist behaviour literature are still limited. To date, the existing studies using this technique generally focus on tourist arrival forecasting and market segmentation issues. The findings of this particular study show that ANNs can be employed for the identification of the impact of destination attributes on customer behavioural intention. In comparison with other analytical techniques, ANNs have some strength in the handling of nonlinear data, without making a priori assumptions about the specific nature of the relationships between inputs and outputs. Their use can also be beneficial in tackling other research issues such as tourism forecasts and market segmentation. In future studies, there is a need to compare the results of ANNs with other analytical techniques such as Structural Equation Models. ANNs exhibit similar patterns to those exhibited by humans. This can be of interest in cognitive sciences and other social 
sciences like tourism which evolve around the behaviour of people. ANNs emulate these patterns with high degree of similarity to the attitudinal and contextual data extracted from an industry domain like tourism.

\section{Managerial implications}

Because of the growing international competition amongst tourism destinations, it is crucial to decide for the tourism practitioners, which attributes and variables determine the behavioural intention of the tourists. By considering the close relationships between destination attributes, customer satisfaction and perceived value variables (e.g.; Heung \& Quf, 2000; Kozak, 2001; Weaver et al., 2007), as well as ANNs' high ability of discovering the hidden knowledge in datasets, researchers of the present study enabled to identify the hidden neurons that have influence on tourist behavioural intention by ANNs. The neurons (in this case; 'Value for Money', 'Basic Functional Attributes', 'Tourist Behaviour Multidimensionality') obtained by ANNs assist practitioners to understand the unexplored behavioural characteristics of the tourism demand. As recommended by Pyo et al. (2002), findings of advanced level analytic techniques such as ANNs require tourism sector authorities' estimations who are expert both in tourism knowledge and data mining. Those experts may use the benefit of accurate knowledge when deciding long-term market strategies and action plans for tourism destinations (Chou \& Chou, 1999). Moreover, by using advanced data mining tools (like ANNs) in tourism sector, practitioners may select potentially new or profitable international segments (Kim, Wei, \& Ruys, 2003; Bloom, 2005) and enhance their strategies in accordance with the "changing behaviour among tourists within and between the macro segments' (Bloom, 2005).

\section{References}

Ahn, T., Ekinci, Y. \& Li, G. (2013). Selfcongruence, functional congruence, and destination choice. Journal of Business Research, 66, 719-723.

Baker, D.A. \& Crompton, J.L. (2000). Quality, satisfaction and behavioral intentions. Annals of Tourism Research, 27(3), 785-804.
Baloglu, S. \& Uysal, M. (1996). Market segments of push and pull motivations: A canonical correlation approach. International Journal of Contemporary Hospitality Management, 8(3), 32-38.

Baum, E.B. \& Haussler, D. (1989). What size net gives valid generalization? Neural Computation, 1, 151-160.

Beerli, A. \& Martin, J.D. (2004). Factors influencing destination image. Annals of Tourism Research, 31(3), 657-681.

Bigne, J.E., Sanchez, M.I. \& Sanchez, J. (2001). Tourism image, evaluation variables and after purchase behaviour: Inter-relationship. Management, 22, 607-616.

Tourism

Bieger, T. (1998). Reengineering destination marketing organisations: The case of Switzerland. Tourism Review, 53, 4-17.

Bloom, J.Z. (2005). Market segmentation: A neural network application. Annals of Tourism Research, 32, 93-111.

Boone, D.S., \& Roehm, M. (2002). Evaluating the appropriateness of market segmentation solutions: Using artificial neural networks and the membership clustering criterion. Marketing Letters, 13(4), 317-333.

Boulding, W., Kalra, A., Staelin, R. \& Zeithaml, V.A. (1993). A dynamic process model of service quality: From expectations to behavioral intentions. Journal of Marketing Research, 30, 7-27.

Čech, P. \& Burěs, V. (2009). Advanced technologies in e-tourism. Proceedings of the 9th WSEAS International Conference on Applied Computer Science (Recent Advances in Applied Computer Science), Ed. Roberto Revetria, Valeri Mladenov, Nikos Mastorakis, University of Genova, Italy, October 17-19, 2009, ISBN: 978960474-127-4, 85-92.

Chen, C-F. \& Tsai, D.C. (2007). How destination image and evaluative factors affect behavioral intentions? Tourism Management, 28, 1115-1122.

Choi, W.M., Chan, A. \& Wu, J. (1999). A qualitative and quantitative assessment of Hong Kong's image as a tourist destination. Tourism Management, 20, 361-365. 
Chou, D.C. \& Chou, A.Y. (1999). A manager's guide to data mining. Information Systems Management, 16(4), 33-41.

Coshall, J.T. (2000). Measurement of tourists' destination images: The repertory grid approach. Journal of Travel Research, 39, 85-89.

Cronin, J.J., Jr., Brady, M.K. \& Hult, G.T.M. (2000). Assessing the effects of quality, value and customer satisfaction on consumer behavioral intentions in service environments. Journal of Retailing, 76(2), 193-218.

Crouch, G.I. \& Ritchie, J.B. (1998). Convention site selection research: A review, conceptual model, and propositional framework. Journal of Convention and Exhibition Management, 1(1), 48-69.

Curry, B. \& Moutinho, L. (1993). Neural networks in marketing: Modeling consumer responses to advertising stimuli. European Journal of Marketing, 27, 5-20.

Dann, G.M.S. (1977). Anomie, egoenhancement and tourism. Annals of Tourism Research, 4(4), 184-94.

Dasgupta, C.G., Dispensa, G. S. \& Ghose, S. (1994). Comparing the predictive performance of a neural network model with some traditional market response models. International Journal of Forecasting, 10, 235-244.

Deng, W. \& Pei, P. (2009). Fuzzy neural based importance-performance analysis for determining critical service attributes. Expert Systems with Applications, 36, 3774-3784.

Duo, J., Guo, W. \& Wang, R. (2007). Tourism room occupancy rate prediction based on neural network. Advances in Neural Networks, 4493, 80-84.

Echtner, C.M. \& Ritchie, J.R.B. (2003). The meaning and measurement of destination image. Journal of Tourism Studies, 14(1), 37-48.

Eusébio, C. \& Vieira, A.L. (2013). Destination attributes' evaluation, satisfaction and behavioural intentions: A structural modelling approach. International Journal of Tourism Research, 15(1), 66-80.

Fallon, P. \& Schofield, P. (2006). The dynamics of destination attribute importance.
Journal of Business Research, 59, 709713.

Hagiwara, M. (1993). Removal of hidden units and weights for backpropagation networks. Proceedings of the International Joint Conference on Neural Networks, 1, 351-354.

Hair, J.F., Ronald, L.T., Rolph, E.A. \& William, B. (1998). Multivariate data analysis. Englewood Cliffs: NJ, USA, Prentice Hall.

Heung, V.C.S. \& Quf, H. (2000). Hong Kong as a travel destination: An analysis of Japanese tourists' satisfaction levels, and the likelihood of them recommending Hong Kong to others. Journal of Travel \& Tourism Marketing, 9, 57-80.

Heung, V.C.S., Qu, H. \& Chu, R. (2001). The relationship between vacation factors and socio demographic and travelling characteristics: The case of Japanese leisure travellers. Tourism Management, 22, 259-269.

Huarng, K-H., Moutinho, L. \& Yu, T.H.-K. (2007). An advanced approach to forecasting tourism demand in Taiwan. Journal of Travel \& Tourism Marketing, $21,15-24$

Hutchinson, J., Lai, F. \& Wang, Y. (2009). Understanding the relationships of quality, value, equity, satisfaction, and behavioral intentions among golf travellers. Tourism Management, 30, 298-308.

Kau, A.K. \& Lim, P.S. (2005). Clustering of Chinese tourists to Singapore: An analysis of their motivations, values and satisfaction. International Journal of Tourism Research, 7, 231-248.

Kim, J., Wei, S. \& Ruys, H. (2003). Segmenting the market of West Australian senior tourists using an artificial neural network. Tourism Management, 24, 2534.

Klenosky, D.B. (2002). The "pull" of tourism destinations: A means-end investigation. Journal of Travel Research, 40, 385-395.

Kozak, M. (2001). Comparative assessment of tourist satisfaction with destinations across two nationalities. Tourism Management, 22, 391-401. 
Kozak, M. \& Rimmington, M. (2000).Tourist satisfaction with Mallorca, Spain, as an off-season holiday destination. Journal of Travel Research, 38, 260-269.

Kuo, R.J. (2001). A sales forecasting system based on fuzzy neural network with initial weights generated by genetic algorithm. European Journal of Operational Research, 129, 496-517.

Law, R. \& Au, N. (1999). A neural network model to forecast Japanese demand for travel to Hong Kong. Tourism Management, 20, 89-97.

Law, R. (2000). Back-propagation learning in improving the accuracy of neural network-based tourism demand forecasting. Tourism Management, 21(4), 331-340.

Law, R., Mok, H. \& Goh, C. (2007). Data mining in tourism demand analysis: A retrospective analysis. Advanced Data Mining and Applications, 4632, 508515.

Li, S. (2000). The development of a hybrid intelligent system for developing marketing strategy. Decision Support Systems, 27, 395-409.

Litvin, S.W. \& Ling, S.N.S. (2001). The destination attribute management model: An empirical application to Bintan, Indonesia. Tourism Management, 22, 481-492.

Looney, C.G. (1996). Advances in feedforward neural networks: Demystifying knowledge acquiring black boxes. IEEE Transactions on Knowledge and Data Engineering, 8, 211-226.

Mazanec, J. (1992). Classifying tourists into market segments: A neural network approach. Journal of Travel and Tourism Marketing, 1, 39-59.

Meng, F., Tepanon, Y. \& Uysal, M. (2008). Measuring tourist satisfaction by attribute and motivation: The case of a nature-based resort. Journal of Vacation Marketing, 14(1), 41-56.

Mikulić, J. \& Prebežac, B. (2012). Accounting for dynamics in attribute-importance and for competitor performance to enhance reliability of BPNN-based importance-performance analysis. Expert Systems with Applications, 39, 5144-5153.
Mitchell, V-W., Davies F., Moutinho, L. \& Vassos, V. (1999). Using neural networks to understand service risk in the holiday product. Journal of Business Research, 46(2), 167-180.

Moutinho, L., Huarng, K-H., Yu, T.H.-K. \& Chen, C-H. (2008). Modeling and forecasting tourism demand: The case of flows mainland China to Taiwan. Service Business, 2, 219-232.

Moutinho, L., Albayrak, T. \& Caber, M. (2012). How far does overall service quality of a destination affect customers' postpurchase behaviour? International Journal of Tourism Research, 14, 307322.

Palmer, A., Montano, J.J. \& Sese, A. (2006). Designing an artificial neural network for forecasting tourism time series. Tourism Management, 27, 781-790.

Pike, S. (2002). Destination image analysis-a review of 142 papers from 1973 to 2000. Tourism Management, 23, 541549.

Pike, S. (2003). The use of repertory grid analysis to elicit salient short-break holiday destination attributes in New Zealand. Journal of Travel Research, 41, 315-319.

Pikkemaat, B. (2004). The measurement of destination image: The case of Austria. The Poznan University of Economics Review, 4(1), 87-102.

Pyo, S., Uysal, M. \& Chang, H. (2002). Knowledge discovery in database for tourist destinations. Journal of Travel Research, 40, 396-403.

Rumelhart, D.E., Widrow, B. \& Lehr, M.A. (1994). The basic ideas in neural networks. Communications of the ACM, 37(3), 87-92.

Shimp, T.A. \& Sharma, S. (1987). Consumer ethnocentrism: Construction and validation of the CETSCALE. Journal of Marketing Research, 24, 280-289.

Thieme, R.J., Song, M. \& Calantone, R.J. (2000). Artificial neural network decision support system for new product development project selection. Journal of Marketing Research, 37, 499-507.

Tosun, C., Temizkan, S.P., Timothy, D.J. \& Fyall, A. (2007). Tourist shopping 
experiences and satisfaction. International Journal of Tourism Research, 9, 87-102.

Truong, T.H. \& Foster, D. (2006).Using HOLSAT to evaluate tourist satisfaction at destinations: The case of Australian holidaymakers in Vietnam. Tourism Management, 27, 842-855.

Tsaur, S., Chiu, Y. \& Huang, C. (2002). Determinants of guest loyalty to international tourist hotels- A neural network approach. Tourism Management, 25, 367-374.

Um, S., Chon, K. \& Ro, Y-H. (2006). Antecedents of revisit intention. Annals of Tourism Research, 33(4), 11411158.

Uysal, M. \& El Roubi, M.S.E. (1999). Artificial neural networks versus multiple regression in tourism demand analysis. Journal of Travel Research, 38, 111118.

Uysal, M. (2004). Advancement in computing: Implications for tourism and hospitality. Scandinavian Journal of Hospitality and Tourism, 4, 208-224.

Venugopal, V. \& Baets, W. (1994). Neural networks and statistical techniques in marketing research: A conceptual comparison. Marketing Intelligence \& Planning, 12, 30-38.
Wang, S. (1998). An insight into the standard backpropagation model for regression analysis. Omega: International Journal of Management Science, 26, 133-140.

Weaver P.A., Weber K. \& McCleary, KW. (2007). Destination evaluation: The role of previous travel experience and trip characteristics. Journal of Travel Research, 45, 333-344.

West, P.M., Brockett, P.L. \& Golden, L.L. (1997). A comparative analysis of neural networks and statistical methods for predicting consumer choice. Marketing Science, 16, 370-391.

Yoon, Y. \& Uysal, M. (2005). An examination of the effects of motivation and satisfaction on destination loyalty: A structural model. Tourism Management, 26, 45-56.

You, X., OLeary, J., Morrison, A. \& Hong, G.S. (2000). A cross-cultural comparison of travel push and pull factors. International Journal of Hospitality \& Tourism Administration, 1(2), 1-26.

Žabkar, V., Brenčič, M. \& Dmitrović, T. (2010). Modelling perceived quality, visitor satisfaction and behavioural intentions at the destination level. Tourism Management, 31, 537-546. 